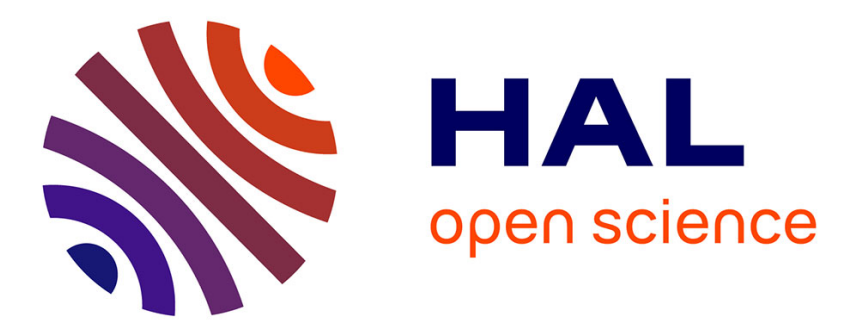

\title{
Modeling and experiments on diffusion and activation of phosphorus in germanium
}

P. Tsouroutas, D. Tsoukalas, I. Zergioti, Nikolay Cherkashin, Alain Claverie

\section{To cite this version:}

P. Tsouroutas, D. Tsoukalas, I. Zergioti, Nikolay Cherkashin, Alain Claverie. Modeling and experiments on diffusion and activation of phosphorus in germanium. Journal of Applied Physics, 2009, 105 (9), pp.094910. 10.1063/1.3117485 . hal-01736053

\section{HAL Id: hal-01736053 https://hal.science/hal-01736053}

Submitted on 23 Mar 2018

HAL is a multi-disciplinary open access archive for the deposit and dissemination of scientific research documents, whether they are published or not. The documents may come from teaching and research institutions in France or abroad, or from public or private research centers.
L'archive ouverte pluridisciplinaire HAL, est destinée au dépôt et à la diffusion de documents scientifiques de niveau recherche, publiés ou non, émanant des établissements d'enseignement et de recherche français ou étrangers, des laboratoires publics ou privés. 


\section{Modeling and experiments on diffusion and activation of phosphorus in germanium}

P. Tsouroutas, D. Tsoukalas, I. Zergioti, N. Cherkashin, and A. Claverie

Citation: Journal of Applied Physics 105, 094910 (2009); doi: 10.1063/1.3117485

View online: https://doi.org/10.1063/1.3117485

View Table of Contents: http://aip.scitation.org/toc/jap/105/9

Published by the American Institute of Physics

\section{Articles you may be interested in}

Intrinsic and extrinsic diffusion of phosphorus, arsenic, and antimony in germanium

Journal of Applied Physics 103, 033508 (2008); 10.1063/1.2837103

Activation and diffusion studies of ion-implanted $p$ and $n$ dopants in germanium

Applied Physics Letters 83, 3275 (2003); 10.1063/1.1618382

High phosphorous doped germanium: Dopant diffusion and modeling

Journal of Applied Physics 112, 034509 (2012); 10.1063/1.4745020

Mechanisms of boron diffusion in silicon and germanium

Journal of Applied Physics 113, 031101 (2013); 10.1063/1.4763353

Diffusion of n-type dopants in germanium

Applied Physics Reviews 1, 011301 (2014); 10.1063/1.4838215

On the diffusion and activation of ion-implanted n-type dopants in germanium

Journal of Applied Physics 106, 103516 (2009); 10.1063/1.3261838

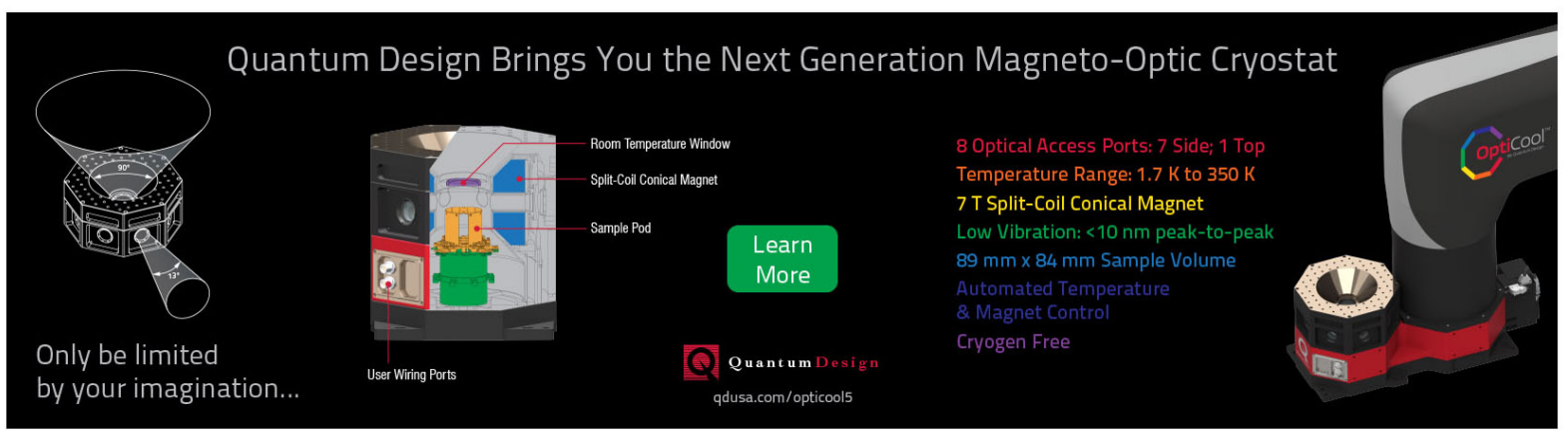




\title{
Modeling and experiments on diffusion and activation of phosphorus in germanium
}

\author{
P. Tsouroutas, ${ }^{1}$ D. Tsoukalas, ${ }^{1, a)}$ I. Zergioti, ${ }^{1}$ N. Cherkashin,${ }^{2}$ and A. Claverie ${ }^{2}$ \\ ${ }^{1}$ Department of Applied Physics, School of Applied Sciences, National Technical University of Athens, \\ 15780 Zographou, Greece \\ ${ }^{2}$ CEMES/CNRS, 29 rue J. Marvig, 31055 Toulouse Cedex 4, France
}

(Received 15 December 2008; accepted 12 March 2009; published online 13 May 2009)

\begin{abstract}
We report on phosphorus diffusion and activation related phenomena in germanium. We have used both conventional thermal processing and laser annealing by pulsed nanosecond Nd:YAG laser. Chemical profiles were obtained by secondary-ion-mass spectroscopy, sheet resistance was estimated by the van der Pauw method, and structural defects were monitored by transmission electron microscopy. Our study covers the temperature range from 440 to $750{ }^{\circ} \mathrm{C}$, and we were able to efficiently simulate the dopant profiles within that temperature range, taking into account a quadratic dependence of the $\mathrm{P}$ diffusion coefficient on the free electron concentration. To achieve that we have taken into account dopant activation dependence on temperature as well as dopant pile-up near the surface and dopant loss owing to outdiffusion during the annealing. A combined laser thermal treatment above the melting threshold prior to conventional annealing allowed the elimination of the implantation damage, so we could perceive the influence of defects on both transient dopant diffusion and outdiffusion. (C) 2009 American Institute of Physics.
\end{abstract}

[DOI: 10.1063/1.3117485]

\section{INTRODUCTION}

Innovative device design and new materials are currently being investigated because of the approaching limit for downscaling CMOS technology. In this context a renewed interest has been observed in germanium as a possible candidate to replace silicon in future MOSFET technology because of its appealing properties such as higher carrier mobility. ${ }^{1-4}$ Critical issues concerning diffusion and activation of dopants that will determine the feasibility of germanium as the next generation semiconductor material need, however, to be addressed. Until recently data on diffusion studies in the literature were almost half a century old and focused mainly on the $p-n$ junction and sheet resistance measurements. 5 The latest reports contribute to a better knowledge of germanium properties. They have shown that while for the $p$-type dopant (mostly boron) both a wellbehaved $p^{+} n$ shallow junction and high activation have been realized $^{6-9}$ due to low diffusivity (even without annealing) $)^{10}$ for the $n$-type dopants ( $\mathrm{P}, \mathrm{As}$, and $\mathrm{Sb}$ ), these requirements have not yet been met satisfactorily. Especially in the case of phosphorus, possible reasons for these poor-quality $n^{+} p$ junctions are the high $\mathrm{P}$ diffusivity ${ }^{7,11,12}$ and the difference between chemical solubility limit (estimated approximately at $2 \times 10^{20} \mathrm{~cm}^{-3}$ at $600{ }^{\circ} \mathrm{C}$ ) and the electrical activation [reported at $6 \times 10^{19} \mathrm{~cm}^{-3}$ at $600{ }^{\circ} \mathrm{C}$ (Ref. 13) or 7 $\times 10^{19} \mathrm{~cm}^{-3}$ at $800{ }^{\circ} \mathrm{C}$ (Ref. 14)] as well as the severe dopant loss observed during annealing. ${ }^{7,11,15-20}$ Although recent reports are in general agreement that phosphorus diffusion depends on the square of the electron concentration, the quantitative values deduced for the intrinsic $\mathrm{P}$ diffusion coefficient are different. For example, Chui et al. ${ }^{7}$ reported sig-

${ }^{a)}$ Electronic mail: dtsouk@central.ntua.gr. nificant higher diffusivities for $\mathrm{P}$ diffusion into $\mathrm{Ge}$ than did Brotzmann and Bracht ${ }^{12}$ and Carroll and Koudelka. ${ }^{11}$

As regards dopant and self-diffusion a rather broad consensus on a vacancy assisted mechanism exists, but different views are obtained about the charge state of the defect that mostly influences the dopant movement. Werner et al. ${ }^{21}$ suggested that Ge self-diffusion occurs through single negatively charged and neutral vacancies. For the case of dopant diffusion into Ge substrates Vainonen-Ahlgren et al. ${ }^{22}$ reported from their experimental results that As diffusion takes place through doubly negatively charged and neutral vacancies. According to Bracht and Brotzmann ${ }^{23}$ the previous group misinterpreted the diffusion's quadratic dependence on the free electron concentration in the charge states of vacancies, stating that As diffusion in Ge is not sensitive to the properties of vacancies and reporting that arsenic's diffusion mechanism is through single negatively charged dopantvacancy pairs. In a recent publication Brotzmann et al. ${ }^{24}$ reported on the existence of doubly negatively charged vacancies from their analysis of the simultaneous diffusion of selfand $n$-type dopant atoms in isotopically controlled Ge multilayer structures, stating that the diffusion of all the common donor dopants ( $\mathrm{P}, \mathrm{As}$, and $\mathrm{Sb}$ ) is controlled from single negatively charged donor-vacancy pairs that are also responsible for the observed enhanced diffusion under extrinsic doping conditions. ${ }^{12}$ On the other hand, Mitha et al. ${ }^{25}$ questioned even the predominance of vacancy-mediated As diffusion.

The present work investigates the diffusion of phosphorus in Ge that appears in previous studies as the most attractive solution for all $n$-type dopants. This is because both $\mathrm{As}$ and $\mathrm{Sb}$ dopants have higher diffusivities ${ }^{7,12}$ and also create more severe damage when introduced in Ge crystal by 
implantation that is more difficult to anneal. These dopants also exhibit lower maximum solid solubility, resulting in higher sheet resistance as compared with phosphorus. ${ }^{15}$ In order to understand better the influence of implantation damage on the dopant loss phenomenon during high temperature treatment, we use a comparative study between implanted only and implanted plus laser-annealed (LA) samples under process conditions that eliminate implantation-induced damage. The major part of the paper is then devoted to the estimation of $\mathrm{P}$ diffusivity through simulation of experimental profiles. For that purpose we have made use of commercial simulators, taking into account not only Fermi level dependence of the diffusion coefficient but also the pronounced dopant loss and trapping observed during diffusion in the near surface area. The reduced electrical activation observed from sheet resistance measurements at annealing temperatures below $525{ }^{\circ} \mathrm{C}$ is also considered to achieve good agreement with experiments in a wide temperature range.

\section{EXPERIMENTAL DETAILS}

The substrate wafers used in our study were Ga-doped $p$-type Ge of $\left(\begin{array}{lll}1 & 0 & 0\end{array}\right)$ orientation with a resistivity of $10 \Omega \mathrm{cm}$. Phosphorus (P) ions of $1 \times 10^{15} \mathrm{at} . / \mathrm{cm}^{2}$ dose were implanted into the Ge substrate at $30 \mathrm{keV}$ energy at room temperature tilted by $7^{\circ}$ to the substrate surface normal to minimize the channeling effect. After implantation the wafer was dipped into $10 \% \mathrm{HF}$ in order to obtain a clean surface and cut into two pieces.

One part was then split into smaller samples that were LA by a Nd:YAG laser $(355 \mathrm{~nm})$ using an energy fluence at $4.0 \mathrm{~mJ} / \mathrm{mm}^{2}$. The samples were irradiated with five pulses each. The duration of the laser pulses was at $4 \mathrm{~ns}$ and the repetition frequency of the pulses was at $1 \mathrm{~Hz}$.

The second part of the initial wafer was capped with a $60 \mathrm{~nm}$ thick silicon nitride $\left(\mathrm{Si}_{3} \mathrm{~N}_{4}\right)$ layer deposited by sputtering. After nitride deposition, the wafer was cut into smaller samples with $6 \times 6 \mathrm{~mm}^{2}$ area that were furnaceannealed (FA) at temperatures ranging from 440 to $750{ }^{\circ} \mathrm{C}$ for $30 \mathrm{~min}$ in nitrogen ambient. For comparison reasons some of the LA samples were also nitride-sputtered and FA at $525{ }^{\circ} \mathrm{C}$ for $30 \mathrm{~min}$ in nitrogen ambient. The dopant profiles were monitored by secondary-ion-mass spectrometry (SIMS) using a CAMECA instrument with a $\mathrm{Cs}+$ ion primary beam and a net energy of $9 \mathrm{keV}$. Cross-sectional transmission electron microscopy (TEM) was performed to characterize the structure after major process steps.

\section{RESULTS AND DISCUSSION}

\section{A. Dopant loss}

In a previous paper ${ }^{26}$ we showed that laser annealing above melting of samples implanted with $\mathrm{P}$ germanium results in boxlike profiles down to the melting depth owing to high P diffusivity. Unfortunately, we have not been able to completely eliminate extended defects using laser pulses with energy fluence of up to $3.0 \mathrm{~mJ} / \mathrm{mm}^{2}$ [Fig. 1(b)]. To that end in the present work we have further increased laser energy, and as we show below, we have achieved a defect-free germanium substrate. In this way when the laser energy flu-

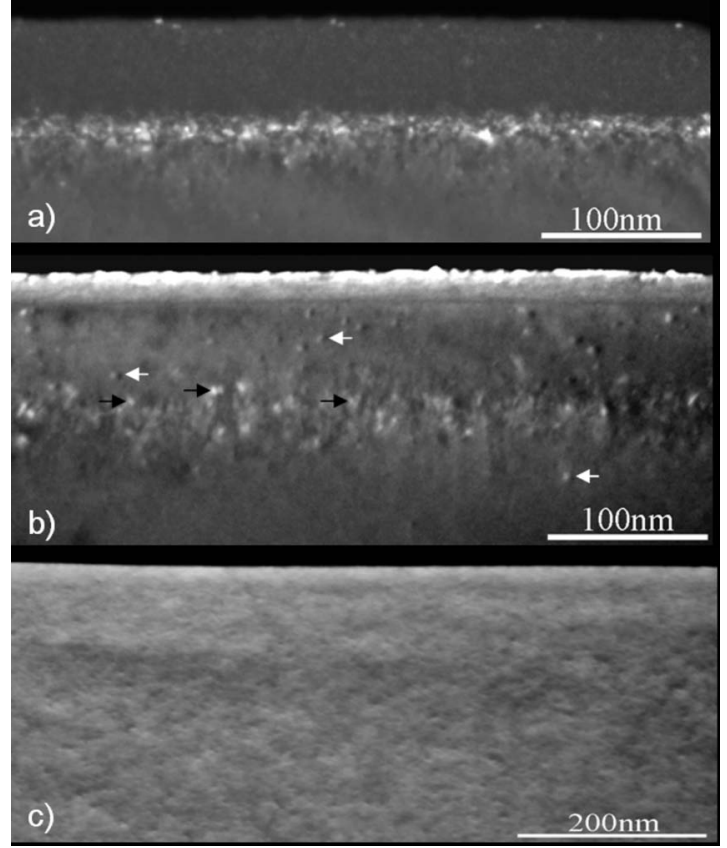

FIG. 1. A series of cross-section TEM images showing (a) the as-implanted area, (b) the laser spot area irradiated with energy fluence of $3 \mathrm{~mJ} / \mathrm{mm}^{2}$, and (c) the laser spot area after irradiated with energy fluence of $4 \mathrm{~mJ} / \mathrm{mm}^{2}$.

ence is increased to $4.0 \mathrm{~mJ} / \mathrm{mm}^{2}$ no defects are observed by TEM [Fig. 1(c)] and complete recrystallization of the material is obtained. Amorphous zone in as-implanted substrates extended down to $65 \mathrm{~nm}$ just after P implantation [Fig. 1(a)].

From SIMS measurements shown in Fig. 2 a boxlike profile for the $4.0 \mathrm{~mJ} / \mathrm{mm}^{2}$ irradiated sample was observed, indicating melting of the substrate near the surface. The profile extended to a depth of $105 \mathrm{~nm}$ and the thermal energy delivered to the substrate was sufficient to generate dopant movement even to the tail region of the profile. From dose integration of the SIMS data corresponding to the LA sample, we obtained a dose reduction of $20 \%$ as compared with the implanted dose. This reduction is smaller than recently reported results after other thermal

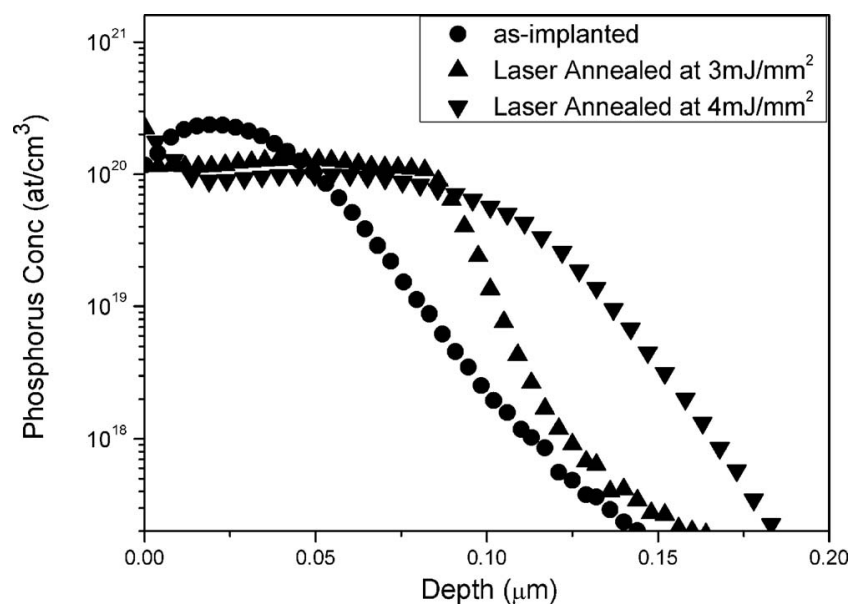

FIG. 2. SIMS measurements showing phosphorus depth profiles for the as-implanted sample and for the samples irradiated with energy fluences of 3 and $4 \mathrm{~mJ} / \mathrm{mm}^{2}$. In order to increase clarity data points shown in the graph are reduced. 


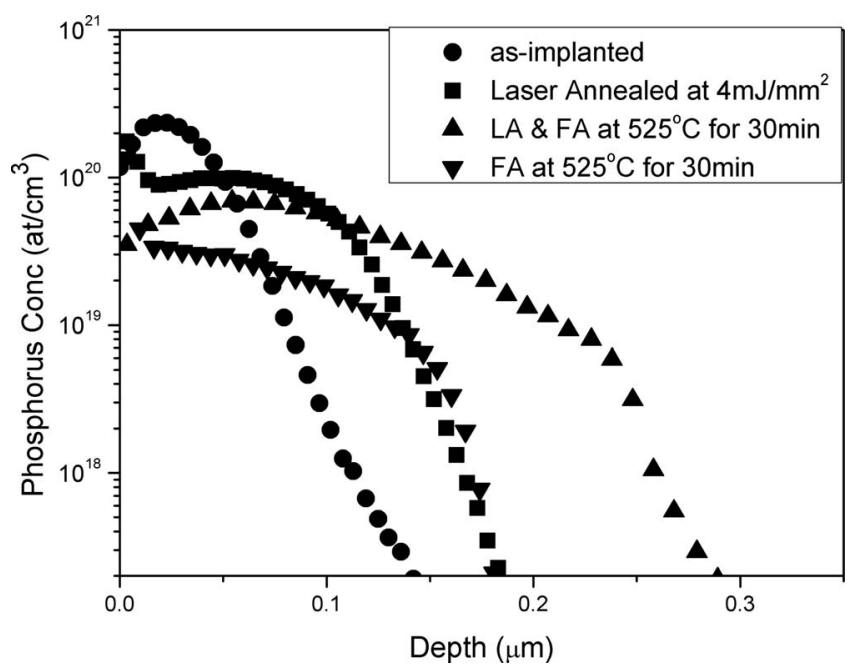

FIG. 3. Phosphorus depth profiles obtained by SIMS measurements showing the effect of conventional furnace annealing at temperature of $525^{\circ} \mathrm{C}$ for $30 \mathrm{~min}$ both at LA $\left(4 \mathrm{~mJ} / \mathrm{mm}^{2}\right)$ and as-implanted areas. Depicted data points are reduced.

treatments, ${ }^{7,8,15,16,18,20}$ given that no capping layer was used in our experiment during the laser-annealing process.

Subsequently we deposited by rf sputtering a $60 \mathrm{~nm}$ thick silicon nitride layer on top of the LA sample. After sputtering, the LA sample underwent a conventional furnace anneal at $525{ }^{\circ} \mathrm{C}$. Dopant profile was measured by SIMS (Fig. 3).

After integration of the SIMS profile we observed no dopant loss for the LA and FA samples at $525^{\circ} \mathrm{C}$ for $30 \mathrm{~min}$. For exactly the same sputtering and annealing conditions the (nonirradiated with laser), FA only sample exhibited a severe dose loss of about $55 \%$ (Fig. 3). This important difference in the dose loss behavior between the two above-mentioned conditions can be attributed to implant damage. The LA samples with almost no implant damage present in the $\mathrm{Ge}$ lattice exhibited no dopant loss for the same annealing temperature and time in contrast with the FA sample that suffered implantation-induced damage. Our observation concerning the specific experimental conditions is in agreement with the suggestion of Poon et al. ${ }^{18}$ that dose loss could be an effect of implant damage.

The depth profile of the LA and FA samples exhibits two characteristics; the first one is a plateau at the region of the peak concentration, and the second is the fast dopant movement toward the substrate occurring at the region between 100 and $240 \mathrm{~nm}$ and the existence of a knee at a concentration of about $4.5 \times 10^{18} \mathrm{~cm}^{-3}$ below which the abrupt profile indicates a very limited dopant movement. This enhanced dopant diffusion can be attributed to a high diffusivity owing to the increased dopant concentration since the outdiffusion is negligible. This profile is accurately simulated in the next section of this paper using proposed models.

\section{B. Diffusion, activation, and simulation}

In a series of experiments we have FA P implanted samples-using the above reported implantation conditions - at a wide range of temperatures from 440 to
$750{ }^{\circ} \mathrm{C}$ for 30 min in $\mathrm{N}_{2}$ in order to study the diffusion and activation of $\mathrm{P}$ in $\mathrm{Ge}$ and estimate the respective diffusion coefficient and activation energy. To simulate the experimental profiles the TCAD simulator TSUPREM IV from Synopsys has been used. Our aim during simulation was to capture not only the dopant loss phenomenon but also the dopant pile-up occurring very close to the surface. For this reason the pile-up model proposed by Normand et al., ${ }^{27}$ which assumes an existence of dopant traps near the surface, was incorporated. It is based on the McNabb and Foster model that considers that the traps are capable of capturing and releasing dopant atoms according to the law of thermal equilibrium. Assuming that $P(x)$ is the concentration of the traps, which are located at the depth $x$ from germanium surface and $\Phi$ $(x, t)$ the fraction occupied at time $t$, the total concentration of the dopants can be expressed as the sum

$$
C_{\text {tot }}(x, t)=C(x, t)+P(x) \Phi(x, t),
$$

where $C(x, t)$ is the concentration of the impurities. Assuming $P(x)=0$ outside the pile-up region (approximately more than $12 \mathrm{~nm}$ from the surface) and $P(x)=P$ inside this region, the one-dimensional diffusion equation controlling the dopant redistribution is defined as

$$
\frac{\partial C(x, t)}{\partial t}+P(x) \frac{\partial \Phi(x, t)}{\partial t}=\frac{\partial}{\partial x}\left[D(C) \frac{\partial C(x, t)}{\partial x}\right]
$$

with

$$
\frac{\partial \Phi(x, t)}{\partial t}=k C(x, t)[1-\Phi(x, t)]-k^{\prime} \Phi(x, t)
$$

The first term $k C(x, t)[1-\Phi(x, t)]$ indicates the rate of capture and the second term $k^{\prime} \Phi(x, t)$ the rate of release independent of the local concentration of the dopants. $k$ and $k^{\prime}$ are the respective reaction constants that are assumed to depend on the nature of the traps. When $k^{\prime}=0$ the above equation describes a permanent dopant capture. Using as parameters the concentration of the traps and the depth of the region where they are present as well as the rates of the trapping and detrapping of the diffused dopant atoms, we have managed to simulate this phenomenon to a great extent.

The dose loss phenomenon was simulated by depositing a virtual oxide onto the germanium substrate and by controlling the segregation coefficient between them. In this way we succeeded in confining the surplus dose in the oxide. Then by stripping the oxide we ensured that the correct dopant dose remained in the substrate.

The chemical solid solubility limit was set at 2 $\times 10^{20} \mathrm{~cm}^{-3}$ and the electrical activation at 6.0 $\times 10^{19} \mathrm{~cm}^{-3}$ for the entire temperature range simulated, which is in accordance with the published reports. ${ }^{13,14}$ The limited data on the electrical activation for the temperature range considered are, however, a source of error for the calculated diffusivity. We have verified with simulation that this error remains small provided the activation level remains close to the one reported in the literature. ${ }^{13,14}$

The general expression of the diffusion coefficient in extrinsic conditions can be described by the following equation: 
TABLE I. Expected sheet resistance as extracted by SIMS depth profiles against measured sheet resistance with the van der Pauw method and the corresponding junction depth $X_{j}$ at concentration $1.0 \times 10^{18} \mathrm{~cm}^{-3}$ for all annealing temperatures ranging from 525 to $750{ }^{\circ} \mathrm{C}$.

\begin{tabular}{cccc}
\hline \hline $\begin{array}{c}\text { Temperature } \\
\left({ }^{\circ} \mathrm{C}\right)\end{array}$ & $\begin{array}{c}\text { Expected } R_{s} \\
(\Omega / \mathrm{sq})\end{array}$ & $\begin{array}{c}\text { Measured } R_{s} \\
(\Omega / \mathrm{sq})\end{array}$ & $\begin{array}{c}X_{j} \\
(\mathrm{~nm})\end{array}$ \\
\hline 525 & 70 & 168 & 174 \\
600 & 58 & 88 & 228 \\
675 & 51 & 60 & 318 \\
700 & 56 & 55 & 366 \\
750 & 43 & 54 & 467 \\
\hline \hline
\end{tabular}

$$
D=D_{o}+D^{-}\left(\frac{n}{n_{i}}\right)+D^{--}\left(\frac{n}{n_{i}}\right)^{2}
$$

where $n$ represents free electrons and $n_{i}$ is the intrinsic electron concentration.

To obtain an estimation of free electron concentration distribution we performed sheet resistance measurements using the four-point van der Pauw method. The sheet resistance $\left(R_{s}\right)$ is related to free electron distribution $(n)$ profile through the following equation:

$$
R_{s}=\frac{1}{\int_{0}^{x_{j}} q \mu(n) n(x) d x} .
$$

The mobility in Eq. (5) is a function of the electron concentration and is calculated using the Hilsum model. ${ }^{28}$ The free electron distribution is first approximated by SIMS measured dopant profile. For each measured value of the sheet resistance we can easily calculate by iterations the P concentration above which the dopant atoms are considered inactive and the free electron distribution becomes consequently flat.

In Table I we present for each experimental condition the value of the measured sheet resistance, the calculated sheet resistance value assuming all dopants are active, and the junction depth. It can be observed that for temperatures higher than $600{ }^{\circ} \mathrm{C}$ most of the impurities are active. For that temperature range any concentration above $10^{19} \mathrm{~cm}^{-3}$ could result in full activation since a very small part of the dopant profile concentration is above this value and consequently influences the sheet resistance value slightly. The value chosen to be used in the simulations for the active $\mathrm{P}$ concentration threshold for temperatures higher than $600{ }^{\circ} \mathrm{C}$ is set at $6 \times 10^{19} \mathrm{~cm}^{-3}$ to be in agreement with previous studies. ${ }^{13}$ For $525{ }^{\circ} \mathrm{C}$ the situation is clearer because the corresponding $\mathrm{P}$ chemical profile expands to much higher concentrations. It is thus possible to estimate in that case that $1 \times 10^{19} \mathrm{~cm}^{-3}$ is the maximum concentration, we can get to have good agreement with measured sheet resistance values since any higher value could lead to inaccurate results.

We note that Hall measurements have been performed in parallel with sheet resistance measurements that reveal each time the conductivity type of the semiconductor. These measurements show as expected a $n$-type material down to $525^{\circ} \mathrm{C}$, but for $440{ }^{\circ} \mathrm{C}$ the semiconductor type is reversed. This has also been observed by other researchers for tem-
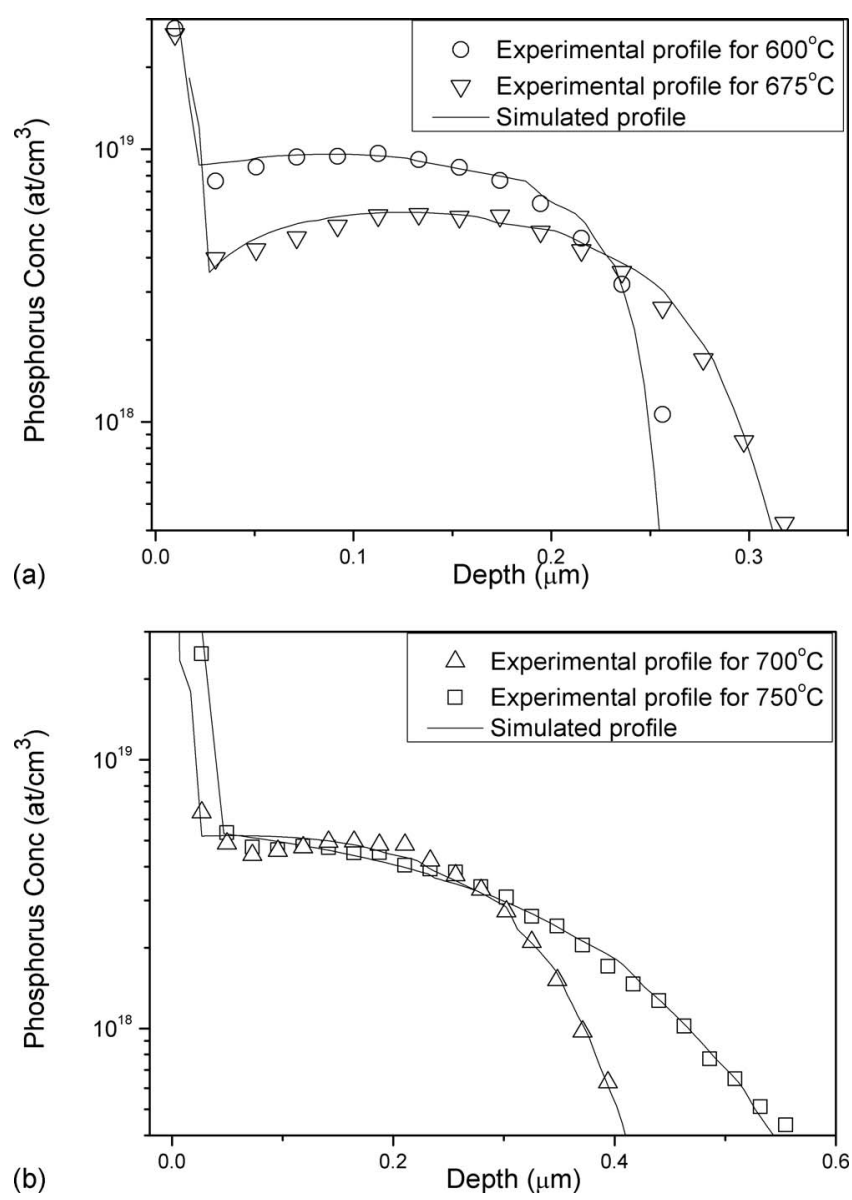

FIG. 4. SIMS depth profiles after furnace annealing at (a) 600 and $675^{\circ} \mathrm{C}$ and (b) 700 and $750{ }^{\circ} \mathrm{C}$ for $30 \mathrm{~min}$ against the best fit simulated profiles (solid lines) obtained by diffusivities reported in this work. Data points are reduced to increase clarity.

peratures lower than $475^{\circ} \mathrm{C}$, and it has been attributed to acceptorlike remaining defects after implantation. ${ }^{29}$

As regards Eq. (4) and in agreement with previous research ${ }^{7,11,12,30}$ the $D^{--}$term was sufficient to reproduce accurately the experimental profiles for the complete temperature range where a sheet resistance measurement was possible. Our effort to fit the above profiles with the use of neutral $\left(D_{O}\right)$ and singly charged terms $\left(D^{-}\right)$both separately and in conjunction produced inaccurate simulation profiles as compared with the experimental ones. For that reason these two diffusivities were set to zero in agreement with the results of Brotzmann and Bracht [see Eq. (2) in Ref. 12]. The quadratic dependence of the diffusivity on the free electron concentration is because of the charge difference between the mobile P-vacancy pair and the substitutional $\mathrm{P}$ donor. $^{23,24}$ In Figs. 4(a) and 4(b) we show the SIMS depth profiles against the diffusion profiles resulting from the simulation for the temperatures of $600,675,700$, and $750{ }^{\circ} \mathrm{C}$, respectively. In Fig. 5 we show the SIMS depth profiles against the simulated profiles for the lower temperatures of 440 and $525^{\circ} \mathrm{C}$, respectively. We remark that the dopant profile distribution at $440{ }^{\circ} \mathrm{C}$ was also accurately simulated using the activation level calculated from the data of $525^{\circ} \mathrm{C}$.

Using the same activation level as above we have also been able accurately to simulate the furnace-annealing step at 


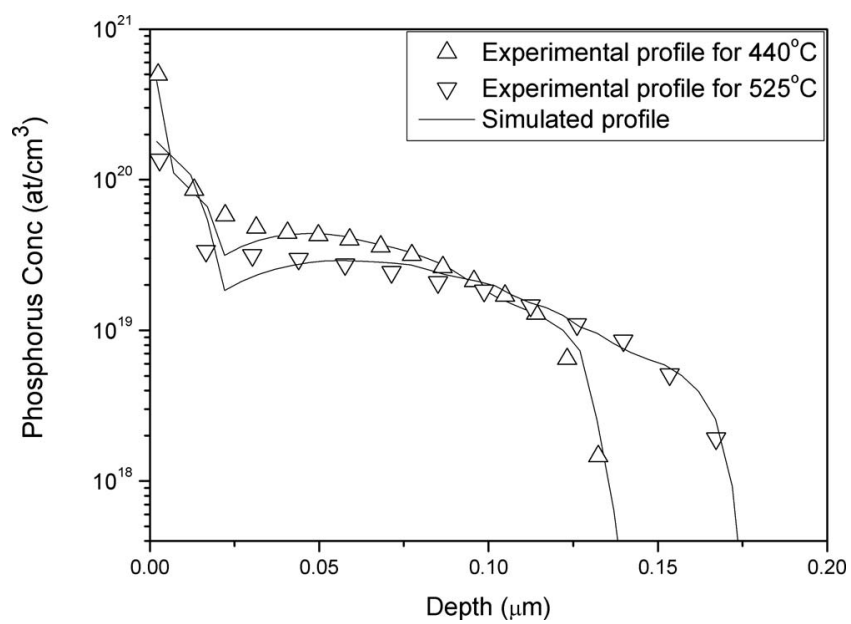

FIG. 5. SIMS depth profile after furnace annealing at $440{ }^{\circ} \mathrm{C}$ (opened triangle up $\Delta$ ) and $525^{\circ} \mathrm{C}$ (opened triangle down $\nabla$ ) for $30 \mathrm{~min}$ against the best fit simulated profiles obtained by doubly charged diffusivity model (solid line) considering a maximum electrical activation of 1.0 $\times 10^{19} \mathrm{~cm}^{-2}$. Data points are reduced.

$525^{\circ} \mathrm{C}$ of the LA sample. This material, as discussed in part A of this section, does not show the presence of any defect prior to the furnace-annealing step and can be considered as an equilibrium situation throughout the complete furnaceannealing time. This simulation is shown in Fig. 6.

It is interesting to note that for the entire range of the annealing temperatures $\left(440-750{ }^{\circ} \mathrm{C}\right)$ the germanium lattice was recovered after the initial damage caused by ion implantation with no visible damage (e.g., extended or EOR defects) as confirmed by the TEM images (Fig. 7). These are images from only FA samples at temperatures of 440 and $600{ }^{\circ} \mathrm{C}$, which show full recrystallization of the germanium crystal. The same applies also to the rest of the temperatures we have used.

\section{Discussion}

In Fig. 8 we show the intrinsic $\mathrm{P}$ diffusion coefficient $\left(D^{-}\right)$deduced from the best fit for each temperature above

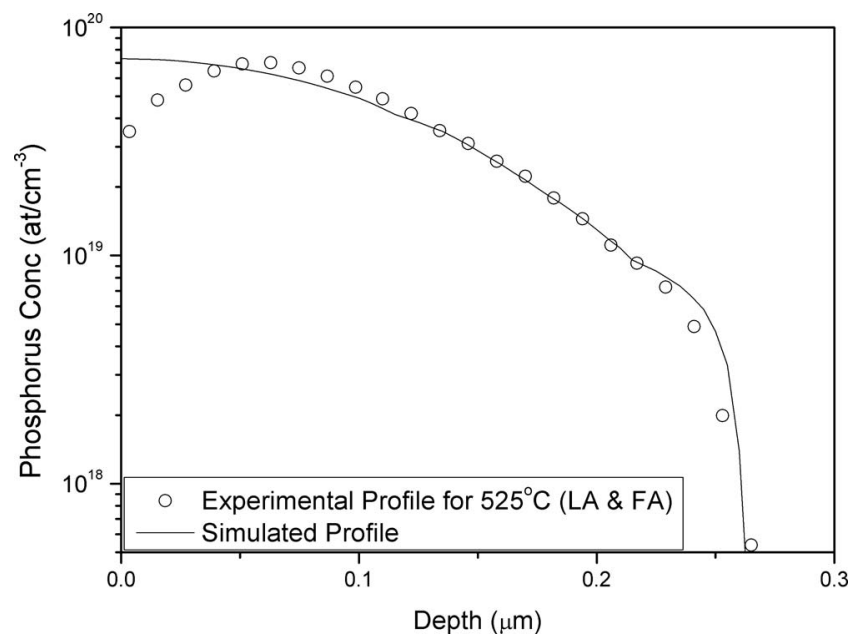

FIG. 6. Phosphorus depth profile obtained by SIMS measurement after conventional furnace annealing at temperature of $525^{\circ} \mathrm{C}$ for $30 \mathrm{~min}$ at LA $\left(4 \mathrm{~mJ} / \mathrm{mm}^{2}\right.$ ) area against the best fit simulated profile obtained by doubly charged diffusivity model (solid line) considering a maximum electrical activation of $1.0 \times 10^{19} \mathrm{~cm}^{-2}$. Depicted data points are reduced for clarity.

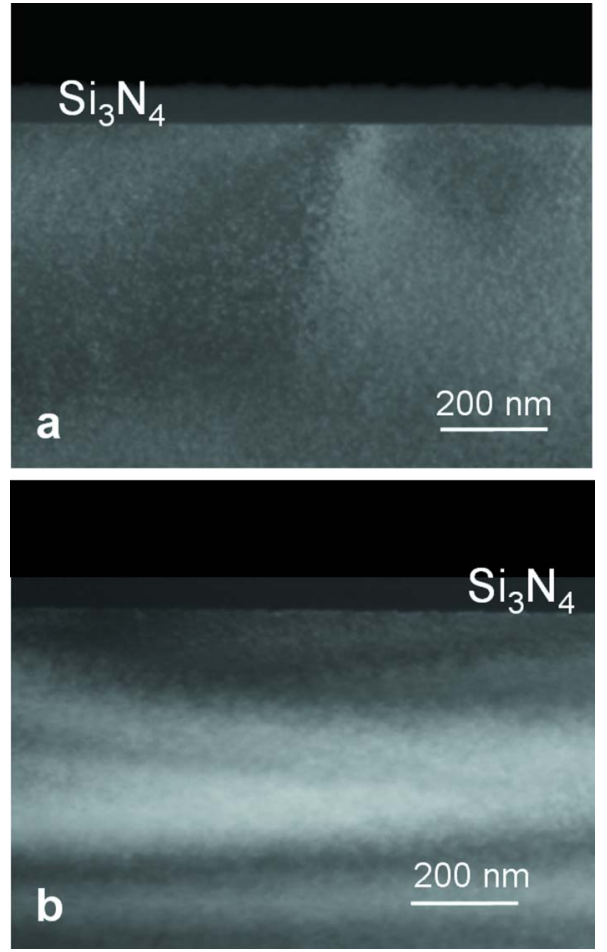

FIG. 7. (Color online) Cross-section TEM images showing the structure after furnace annealing at temperature (a) 440 and (b) $600{ }^{\circ} \mathrm{C}$ for $30 \mathrm{~min}$. The germanium substrate is fully recrystallized with no visible residual damage.

$600{ }^{\circ} \mathrm{C}$ against the diffusivities extracted for the same temperature range from recent investigations of other research groups. ${ }^{7,11,12}$ The diffusivity coefficient versus temperature shows an Arrhenius behavior with an activation energy of $2.69 \mathrm{eV}$. We denote here that the linear fit was performed using only three out of the four diffusivity values corresponding to the different temperatures used. This approach was followed in order to obtain more accurately the extracted values of pre-exponential coefficient and activation energy since the diffusivity coefficient corresponding to the tem-

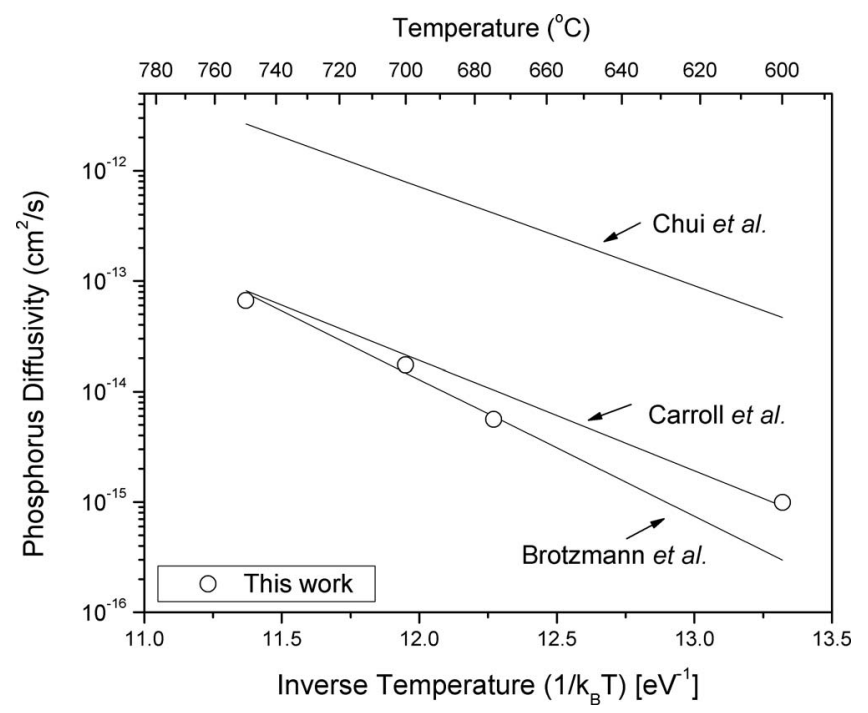

FIG. 8. Extracted doubly charged diffusivities from simulations' best fits compared to extrapolated diffusivities from other groups (Refs. 7, 11, and 12) for temperatures ranging from 600 to $750{ }^{\circ} \mathrm{C}$. 
perature of $600{ }^{\circ} \mathrm{C}$ is more prone to error, owing to the lower activation level of the dopant at that temperature, as concluded from the results shown in Table I. The extracted activation energy $(2.69 \pm 0.21 \mathrm{eV})$ and pre-exponential diffusion coefficient $\left(1.44_{-1.31}^{+15} \mathrm{~cm}^{2} / \mathrm{sec}\right)$ are higher compared than those reported by Chui et al. $^{7}(2.07 \mathrm{eV}, 4.38$ $\left.\times 10^{-2} \mathrm{~cm}^{2} / \mathrm{sec}\right)$ and Carroll and Koudelka ${ }^{11}(2.3 \mathrm{eV}, 1.85$ $\times 10^{-2} \mathrm{~cm}^{2} / \mathrm{sec}$ ) but lower than those of Brotzmann and Bracht $^{12}\left(2.85 \mathrm{eV}, 9.1 \mathrm{~cm}^{2} / \mathrm{sec}\right)$. The intrinsic $\mathrm{P}$ diffusion coefficients deduced from our experimental profiles are in excellent agreement with the results of Brotzmann and Bracht. ${ }^{12}$ What is more striking from the above comparison is that the result of Chui et al. ${ }^{7}$ for the diffusivity is about two orders of magnitude higher than the other three reported values. Possible explanations given by Carroll and Koudelka ${ }^{11}$ for this difference are that these researchers simulated the SRP and not the SIMS profiles, which results in an underestimation of peak concentration, and that they have also scaled the initial dose for each temperature to fit the measured dose after implantation rather than capturing the effect of the dopant loss mechanism on the resulting dopant profile. Another plausible explanation for this difference is the use of the different thermal processing approaches, which the above research groups have followed and, mostly, the different implantation conditions used. The diffusivity measured after RTA, an approach used by Chui et al., ${ }^{7}$ is probably enhanced owing to implant damage similar to the well-known transient enhanced diffusion (TED) effects observed in silicon. By increasing the annealing time the damage is annealed, and the diffusivity enhancement has a much smaller contribution to the measured average diffusivity. The source of point defect injection remains to be identified. One can assume either injection from clustering/declustering of $\mathrm{P}$ at high concentrations or that point defect source is the dissolution of extended defects during the annealing steps. It is worth pointing out that the dose used by Chui et al., ${ }^{7}$ which resulted in extremely high surface concentration for $\mathrm{P}$, was quite high $\left(6 \times 10^{15} \mathrm{~cm}^{-2}\right)$ and the energy $20 \mathrm{keV}$. Damage created after such implantation conditions should behave differently from damage created by lower implanted doses. Further studies related to initial implantation damage as a function of dose are necessary. In the study by Carroll and Koudelka $^{11}$ any influence of TED has been minimized because of the long annealing times used. On the other hand Brotzmann and Bracht ${ }^{12}$ used diffusion from a solid state $\mathrm{P}$ source into Ge substrate where no TED is normally observed. At this point we remark that if we make use of a low intrinsic diffusion coefficient value similar to the one reported by Brotzmann and Bracht, ${ }^{12}$ this will result in nonmovement of $\mathrm{P}$ atoms at intrinsic conditions, something that is experimentally observed from existing data taken from different literature sources. ${ }^{13,20}$

To investigate the existence of TED under implantation conditions we have performed diffusion anneals for small time intervals $(1 \mathrm{~min})$ at $525{ }^{\circ} \mathrm{C}$. The analysis of the SIMS profiles showed no enhanced dopant diffusion to the bulk, demonstrating that for these conditions dopant diffusion is not driven by TED. In addition, simulation of the thermal process of the previously LA sample (Fig. 6) —with no initial damage present as observed by TEM — gives satisfactory results with the same parameters as FA samples just after implantation. This is another evidence of negligible TED at the conditions used in our work.

\section{CONCLUSIONS}

Designed experiments using LA samples show an insignificant dose loss after additional furnace annealing, which is not the case for only FA samples. It appears that dose loss is associated with implantation damage annealing that drives $\mathrm{P}$ atoms out of Ge. The implantation damage in our experimental conditions can be annihilated for temperatures as low as $440^{\circ} \mathrm{C}$, as confirmed by TEM. Simulation of experimental P profiles obtained after annealing in a wide temperature range gives satisfactory results, taking into account a quadratic dependence of the $\mathrm{P}$ diffusion coefficient on the free electron concentration that is in accord with the vacancy mechanism of $\mathrm{P}$ diffusion in Ge proposed by Brotzmann et al. ${ }^{12,24}$ In addition, a segregation coefficient between the cap nitride and Ge substrate modulating the dose loss and a pile-up model to capture the increased dopant concentration very close to the Ge surface was considered. For temperatures below $525{ }^{\circ} \mathrm{C}$ a limited electrical activation needs to be considered due to reduced solid solubility in order to obtain accurate fit to experimental profiles. The estimated intrinsic $\mathrm{P}$ diffusion coefficient is close to the value reported by other researchers $^{11,12}$ with an activation energy of $2.69 \mathrm{eV}$.

\section{ACKNOWLEDGMENTS}

Two of the authors (P.T. and D.T.) would like to acknowledge financial support from Greek GSRT and ST Microelectronics through the PENED program and also Dr. Claude Armand from INSA-Toulouse and Dr. G. Bennassayag CEMES-Toulouse for SIMS measurements.

${ }^{1}$ C. O. Chui, H. Kim, D. Chi, B. B. Triplett, P. C. McIntyre, and K. C. Saraswat, Tech. Dig. - Int. Electron Devices Meet. 2002, 437.

${ }^{2}$ H. Kim, C. O. Chui, K. Saraswat, and P. C. McIntyre, Appl. Phys. Lett. 83, 2647 (2003)

${ }^{3}$ H. Shang, H. Okorn-Schmidt, J. Ott, P. Kozlowski, S. Steen, E. C. Jones,

H. S. Wong, and W. Hanesch, IEEE Electron Device Lett. 24, 242 (2003).

${ }^{4}$ A. Ritenour, S. Yu, M. L. Lee, N. Lu, W. Bai, A. Pitera, E. A. Fitzgerald,

D. L. Kwong, and D. Antoniadis, Tech. Dig. - Int. Electron Devices Meet. 2003, 433.

${ }^{5}$ N. A. Stolwijk and H. Bracht, Diffusion in Silicon, Germanium and Their Alloys, Landolt-Börnstein New Series Vol. III/33 (Springer, New York, 1998).

${ }^{6}$ Germanium-Based Technologies-From Materials to Devices, edited by C. Claeys and E. Simoen (Elsevier, Amsterdam, 2007).

${ }^{7}$ C. O. Chui, K. Gopalakrishnan, P. B. Griffin, J. D. Plummer, and K. C. Saraswat, Appl. Phys. Lett. 83, 3275 (2003).

${ }^{8}$ A. Satta, E. Simoen, T. Clarysse, T. Janssens, A. Benedetti, B. De Jaeger, M. Meuris, and W. Vandervorst, Appl. Phys. Lett. 87, 172109 (2005).

${ }^{9}$ Y. S. Suh, M. S. Carroll, R. A. Levy, G. Bisognin, D. De Salvador, and M. A. Sahiner, IEEE Trans. Electron Devices 52, 2416 (2005).

${ }^{10}$ S. Uppal, A. F. W. Willoughby, J. M. Bonar, A. G. R. Evans, N. E. B. Cowern, R. Morris, and M. G. Dowsett, J. Appl. Phys. 90, 4293 (2001).

${ }^{11}$ M. S. Carroll and R. Koudelka, Semicond. Sci. Technol. 22, S164 (2007).

${ }^{12}$ S. Brotzmann and H. Bracht, J. Appl. Phys. 103, 033508 (2008).

${ }^{13}$ A. Satta, T. Janssens, T. Clarysse, E. Simoen, M. Meuris, A. Benedetti, I. Hoflijk, B. De Jaeger, C. Demeurisse, and W. Vandervorst, J. Vac. Sci. Technol. B 24, 494 (2006).

${ }^{14}$ V. I. Fistul, A. G. Yakovenko, A. A. Gvelesiani, V. N. Tsygankov, and R. L. Korchazhkina, Inorg. Mater. 11, 457 (1975). 
${ }^{15}$ E. Simoen, A. Satta, A. D'Amore, T. Janssens, T. Clarysse, K. Martens, B. De Jaeger, A. Benedetti, I. Hoflijk, B. Brijs, M. Meuris, and W. Vandervorst, Mater. Sci. Semicond. Process. 9, 634 (2006).

${ }^{16}$ A. Satta, E. Simoen, T. Janssens, T. Clarysse, B. De Jaeger, A. Benedetti, I. Hoflijk, B. Brijs, M. Meuris, and W. Vandervorst, J. Electrochem. Soc. 153, G229 (2006).

${ }^{17}$ C. Jasper, L. Rubin, C. Lindfors, K. S. Jones, and J. Oh, Proceedings of Ion Implantation Techniques (IEEE, New York, 2002), p. 548.

${ }^{18}$ C. H. Poon, L. S. Tan, B. J. Cho, and A. Y. Du. J. Electrochem. Soc. 152, G895 (2005).

${ }^{19}$ T. Janssens, C. Huyghebaert, D. Vanhaeren, G. Winderickx, A. Satta, M. Meuris, and W. Vandervost, J. Vac. Sci. Technol. B 24, 510 (2006).

${ }^{20}$ A. Chroneos, D. Skarlatos, C. Tsamis, A. Christofi, D. S. McPhail, and R. Hung, Mater. Sci. Semicond. Process. 9, 640 (2006).

${ }^{21}$ M. Werner, H. Mehrer, and H. D. Hochheimer, Phys. Rev. B 32, 3930 (1985).

${ }^{22}$ E. Vainonen-Ahlgren, T. Ahlgren, J. Likonen, S. Lehto, J. Keinonen, W. Li, and J. Haapamaa, Appl. Phys. Lett. 77, 690 (2000).
${ }^{23}$ H. Bracht and S. Brotzmann, Mater. Sci. Semicond. Process. 9, 471 (2006).

${ }^{24}$ S. Brotzmann, H. Bracht, J. Lundsgaard Hansen, A. Nylandsted Larsen, E. Simoen, E. E. Haller, J. S. Christensen, and P. Werner, Phys. Rev. B 77, 235207 (2008).

${ }^{25}$ S. Mitha, M. J. Azizb, D. Schiferl, and D. B. Poker, Appl. Phys. Lett. 69, 922 (1996).

${ }^{26}$ P. Tsouroutas, D. Tsoukalas, A. Florakis, I. Zergioti, A. A. Serafetinides, N. Cherkashin, B. Marty, and A. Claverie, Mater. Sci. Semicond. Process. 9, 644 (2006).

${ }^{27}$ P. Normand, D. Tsoukalas, N. Guillemot, and P. Chenevier, J. Appl. Phys. 66, 3585 (1989).

${ }^{28}$ C. Hilsum, Electron. Lett. 10, 259 (1974).

${ }^{29}$ K. Benourhazi and J. P. Ponpon, Nucl. Instrum. Methods Phys. Res. B 71, 406 (1992).

${ }^{30}$ M. Naganawa, Y. Shimizu, M. Uematsu, K. M. Itoh, K. Sawano, Y. Shiraki, and E. E. Haller, Appl. Phys. Lett. 93, 191905 (2008). 